\title{
Increasing the efficiency of coal mining based on the concept of Shewhart-Deming variability management
}

\author{
Vadim Mikhalchenko ${ }^{1, *}$, Yuryi Rubanik $^{2}$ \\ ${ }^{1}$ T.F. Gorbachev Kuzbass State Technical University, Institute of Economy and \\ Management, Department of Economics, 28, Vesennaya str., Kemerovo, Russia \\ ${ }^{2}$ New Management Technologies Centre, Moscow, Russia
}

\begin{abstract}
The article reveals the key moments and technology of the administrative decision-making on the basis of concepts of the theory of variability that is an integral part of the "Deep Knowledge System" by E. Deming. This system is the theoretical basis of modern management, i.e. quality management. Quality management shifts the focus of managers from machines to people and the quality of all processes implemented in the business system. The main idea of quality management is continuous improvement of processes, reduction of variability and search for solutions aimed at maximizing customer satisfaction. In order to proceed to practical steps to solve the problems of business efficiency, it is first of all necessary to achieve an appropriate level of theoretical understanding of the origins of the formation of this effectiveness. Understanding the fundamentals of the theory of variability is a necessary condition for making a rational management decision. Control cards are an effective tool for developing the right management solution, they are designed for continuous monitoring and diagnostics of the state of business processes. The examples of control charts considered in the article in a generalized form characterize the "resulting" variability in coal mining enterprises, and the results of their analysis indicate to managers the direction of searching for ways to increase the efficiency of coal mining.
\end{abstract}

\section{Introduction}

In accordance with the provisions of the modern management theory - quality-based management [1-8], the success of the organization is determined to $95 \%$ by system factors and, thus, the latter are a potential reserve to improve its effectiveness. In this case, all or the vast majority of system factors, like the purpose of the system, are under control and can only be changed at the highest level of management of the organization, i.e. by top management. Recognition of this circumstance caused a radical revision of the role of the leaders of the organization. It consists in creating conditions within the organization that maximize the full use of its resources including human resources.

\footnotetext{
* Corresponding author: v.mikhalchenko@mail.ru
} 
The well-known management specialist Myron Tribus described the situation as follows: "People work in the system. The task of the manager is to work on the system, improving it with their help. ... Only top-level managers are authorized to make changes to the system, and if you personally do not do this as a manager, then the matter will not be done. Your production as a whole will be feverish. As a manager, you can not absolve yourself of the responsibility for the quality of management of production processes for which you are required to respond. And if you can shift this responsibility to someone, then do we need you? "[9].

From the above, it follows that to increase the efficiency of business it is important to establish not the one who is to blame, but what needs to be done to improve the system and achieve better results.

Solving of this problem requires constant monitoring of the state of the system, monitoring of the variability (change) of parameters of its processes, analysis of collected statistics, development of improvement programs and their implementation.

\section{Methods}

Until recently, the so-called "engineering" approach is widely used in management practice, when the assessment of the state of the system is carried out in terms of compliance of process parameters with established requirements, norms and tolerances. With this approach, the results of processes and the state of systems are evaluated as "satisfactory" or "unsatisfactory", "bad" or "good".

The limitation of the traditional approach is that it does not provide guidance and necessary information on optimal ways to improve the process, how the manager should act.

The solution of this problem in the early 20 s of the twentieth century was proposed by W. Shewhart $[10,11]$, developing the concept of variability management, which was subsequently developed and supplemented by E. Deming [12].

The concept of the Shewhart-Deming variability is based on the principle of separating all the causes of variability into two main types:

- "common" causes of variability - are potentially inherent in the process or system, manifest constantly, hour after hour, day after day and affect everyone who participates in a particular process;

- "special" causes of variability - are not a permanent part of the system, they can only detect themselves at certain periods of time, do not appear on all participants in the system and are the result of certain factors.

For example, the productivity and quality of labor of all workers in the shop are influenced by factors that are common to all: indoor lighting, temperature, ventilation quality, adopted processing technology, the adopted system of staff selection and training, labor remuneration, etc. But there are factors that are specific to individual workers. Some of them may feel ill due to illness. Someone has problems in the family, and all his attention is focused on these problems, the other has gone wrong with the machine, and as a result, the quality of his work has significantly decreased. This example demonstrates the importance of understanding the type of variability that one has to deal with in a particular case before any management decision is made. A process or system whose results are influenced only by "common" causes of variability, W. Shewhart proposed to call "stable" or "manageable". Such systems are in a state of "statistical control". This does not mean that there is no variability at the output of the process or that the degree of this variability is small and is within the tolerances. No! Stability of the process means only one thing: the variability of its outputs is statistically predictable, that is, the probability of their being found in a certain range of values can be indicated. 
The process, the results of which are determined by the joint action of "common" and "special" causes of variability, is called unstable. Instability does not mean that this process produces results with a high degree of dispersion. It is called unstable because the magnitude of this spread and, consequently, the probability of its various values appearing varies unpredictably in time.

The approach to the analysis of manifestations of variability, in terms of the type of causative factors, is fundamentally different from the traditional one, based on the "engineering" approach. As shown by W. Shewhart, methods of variability management should differ significantly for stable and unstable processes.

In particular, W. Shewhart justified and formulated the following rules of variability management:

1. It is ineffective to attempt to identify and eliminate the causes of individual deviations, when variations arise in a stable process.

2. It is effective to identify and eliminate the cause of individual large deviations in an unstable process.

W. Shewhart proposed an effective tool for classifying the type of causal factors of variability and determining the state of the process "stable" or "unstable" - the so-called "control card" (Fig. 1).

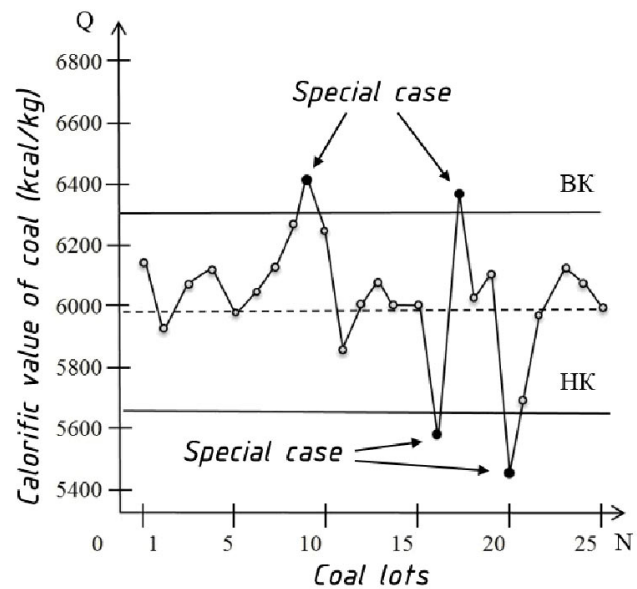

Fig. 1. Control card for coal calorific value in lots for export

The control card can be constructed on the basis of data on the change in time of the controlled parameters or characteristics in the process of interest to us. It can be quality parameters (calorific value, moisture, ash content of mined coal), production indicators (volume of production, processing or shipment for individual calendar intervals), statistics of injuries, absenteeism, etc. These statistical characteristics are plotted on a control card.

The center line on the control card is the average value of the statistical characteristic for the parameter under study. The upper (BK) and lower control boundaries (HK) are calculated according to certain relationships based on the same data. In the simplest case, the upper and lower control boundaries are defined by the relations:

$B K=\bar{x}+3 \sigma_{x} ; H K=\bar{x}-3 \sigma_{x}$,

where $\bar{x}=\frac{\sum_{i}^{N} x_{i}}{N}-$ mean value of the studied variable in the sample under analysis $\{\mathrm{x} 1$, $\mathrm{x} 2 \ldots, \mathrm{xn}\}$; 
$\sigma_{x}=\sqrt{\frac{1}{N-1} \sum_{i}^{N}\left(\bar{x}-x_{i}\right)^{2}}-$ RMS deviation estimated for this sample.

The process is considered stable if the values of the variable are within the control limits, in spite of the fact that some of the points, being within these boundaries, do not satisfy the requirements for this parameter. The control boundaries fix the range of possible fluctuations in the values of the variable being studied. Points that fall outside the control boundaries indicate the appearance of special causes of variability, the instability of the process.

The general algorithm of actions of the manager for the implementation of the concept of continuous improvement of processes and systems is given below.

At the first step of the process monitoring, based on the analysis of the control card data, the type of the system is set.

If the system is "unstable", it is necessary to identify and eliminate the causal factors that predetermine the occurrence of "special" cases and, thus, lead the system in a "stable" state.

If the process (system) is "stable", the decision maker does not respond to individual deviations of the process (system) parameters, but performs continuous monitoring and evaluation of the effectiveness of this process (system).

In case of unsatisfactory performance of the "stable" system, it is necessary to identify the most significant "common" causal factors of variability and eliminate their negative impact on the process (system). In the future, if the parameters of the process satisfy the effectiveness requirements, the decision-maker monitors the indicators until the moment of its completion without interfering in the process of its development and does not react to individual deviations of its parameters.

The main responsibility for identifying the specific reasons for the variability of the unstable process rests with the workers who directly implement this process, although they may need help from managers and engineering staff. Responsibility for revealing factors of common causes of the variability of a stable process lies with the engineering staff and the leaders.

At the same time, the responsibility for introducing changes into the system lies almost entirely with the leaders of the organization.

Heads of organizations are responsible for creating a system that should initiate and implement the process of change. The process of change presupposes training of all employees in the organization, from top managers to workers, on the basics of the concept of variability management and methods of control and management.

It is necessary to emphasize that the enormous potential opportunities that open before organizations that consistently realize the knowledge of the basics of the concept of variability can be realized in full only if mastering and practical use of this knowledge begins with the top management. The control cards of key performance indicators of the enterprise built by the managers of these enterprises present the greatest value and importance.

To date, the techniques of statistical analysis and, in the first place, the toolkit of control cards at all levels of management and in various spheres of business activity have been well studied and a large number of publications on this issue have been presented in considerable detail (13-16).

As in other industries, the concept of variability can be used in the coal mining industry. Moreover, in comparison with other industries, in coal mining there is a certain specificity consisting in the fact that the effectiveness of its processes is largely influenced by factors that do not depend on human will, namely, the variability of natural conditions. Laid over the technical, technological and organizational variability generated by the imperfection of 
human activity, this "wave", increasing and causing significant losses, spreads to related industries, reaches final consumers, ultimately determining the level and quality of people's lives. In this regard, mastering the fundamentals of the Shewhart-Deming variability concept by the managers of coal mining enterprises and the implementation of this knowledge in practical activities acquires high relevance and becomes a critically important and necessary condition for ensuring competitive advantages and survival of coal-mining enterprises in the current economic conditions.

\section{Results and discussions}

Let's consider some examples of application of the concept of variability in real management practice at the coal-mining enterprise. At the same time, we will focus not so much on the technique of constructing control cards, but on those conclusions that follow from understanding the concept of variability for engineering and management practice.

From the point of view of the end user, the performance of the coal mining enterprise can be assessed by a set of characteristics that determine the consumer value of its product and include the following three main groups.

The first group is the product quality indicators that characterize its functional purpose (calorific value, chemical composition, ash content, etc.).

The second group of indicators characterizes the terms of delivery, including the most important of them - the prompt delivery, its reliability (accuracy of compliance with the schedule).

The third group of indicators is economic. The most significant of all possible economic indicators for the end consumer is the price of products at the point of consumption.

Figures 1, 2, 3, and 4 show the data characterizing the typical for coal mining operations level of variability of the indicated groups of users.

In particular, Fig. 1 illustrates the variability in the level of caloric value of Russian coal received from Kuzbass, a large coal-mining region of Russia, by one of the foreign consumers. As it follows from Fig. 1, from the standpoint of the end user, the process of formation of the functional properties of coal is unstable.

Deviations from the average level of quality cannot be explained by the presence of only system-wide variations, since special reasons for variations also occur. At the same time, fluctuations are possible both in the direction of reduction and in excess of the expected "natural" spread of the calorific value of coal, which indicates the absence of a system in the formation of the quality of coal supplied.

In this situation, in accordance with the recommendations discussed above, the optimal strategy involves conducting an immediate analysis and eliminating the reasons for undesirable fluctuations in the quality of the supplied coal in cases where it exceeds the control limits identified on the control card. The consistent detection and prevention of further manifestation of the specific causes of variability will allow stabilizing the situation - to form a system for ensuring the quality of the supplied coal.

Fig. 2 presents data characterizing the delay in the implementation of the agreed schedule of coal supply to consumers.

This indicator directly characterizes both the efficiency and reliability of the coal supply process. As follows from the figure, the delivery process can be considered as stable: all points on the control card fit within the control limits (the НКГ has negative values and is assumed to be 0 ). This means that the observed variability is completely determined by the existing system of organization, management and delivery. However, the statement of the conditions of stability does not mean that the consumer is satisfied with the existing state of affairs. As the control card shows, the average delay is 1-2 months relative to the agreed delivery schedule. At the same time, delays in the beginning of the delivery, reaching 3-4 
months, are observed steadily and predictably. Moreover, we can expect a delay of 4-5 months within the framework of the current system. In this case, such a large deviation cannot be regarded as a special case - it fits perfectly into the control boundaries. It can be said that the existing system of organization and management of the supply process is "ideally adapted", that it is stable to give the observed backlog from the delivery schedule.

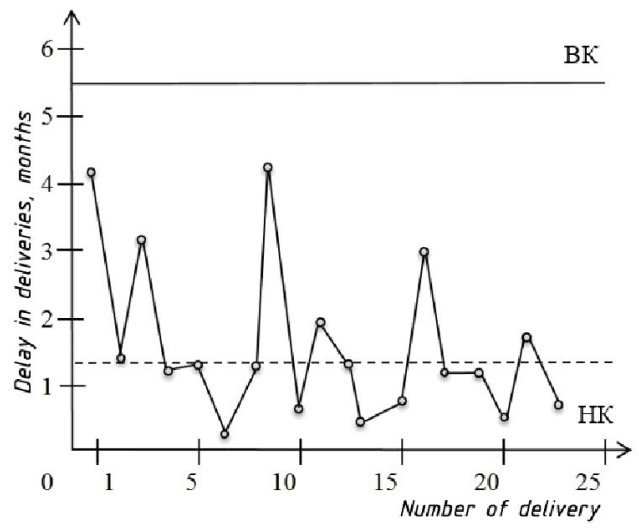

Fig. 2. Control card for the indicator of deviation from the start of coal deliveries for export as per the agreed schedule

The theory of variability determines the optimal actions in this situation: it is pointless to find out the reasons and a person to be blamed for large delays in the delivery under individual contracts. In Figures 3 and 4 there are control cards for the indicators of technical and economic efficiency of a group of coal-mining open-pit mines of Kuzbass. As it follows from the analysis of these control cards, despite the significant differences in the technical and economic indicators that characterize various enterprises, they all belong to the same system. In this case, this means that from the point of view of the applied design methods, the technology of mining, the methods of management and organization of labor, all these enterprises are the same. Differences in technical and economic efficiency are due to some random coincidence, which is characteristic for this moment, as well as a complex interconnection of factors common to all enterprises.

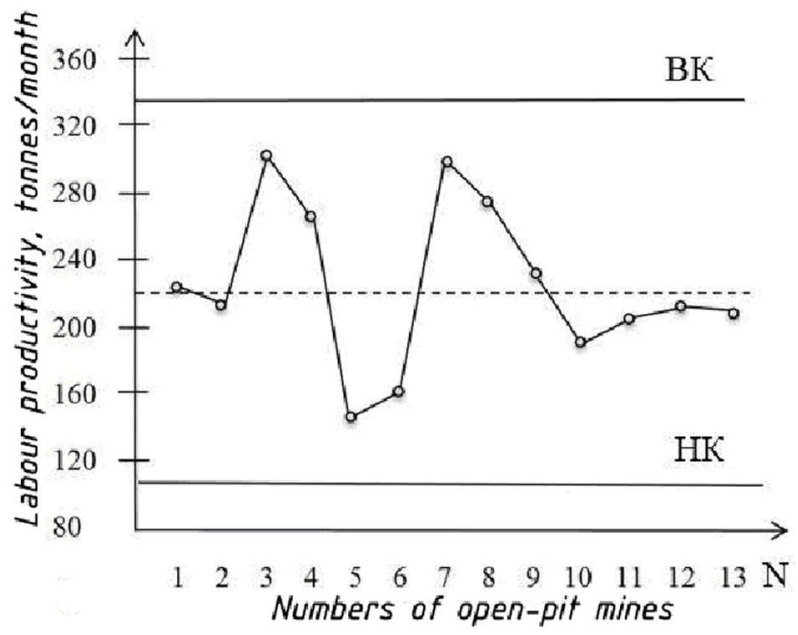

Fig. 3. Control card for workers' labour productivity indicators of a group of coal mining enterprises of Kuzbass 


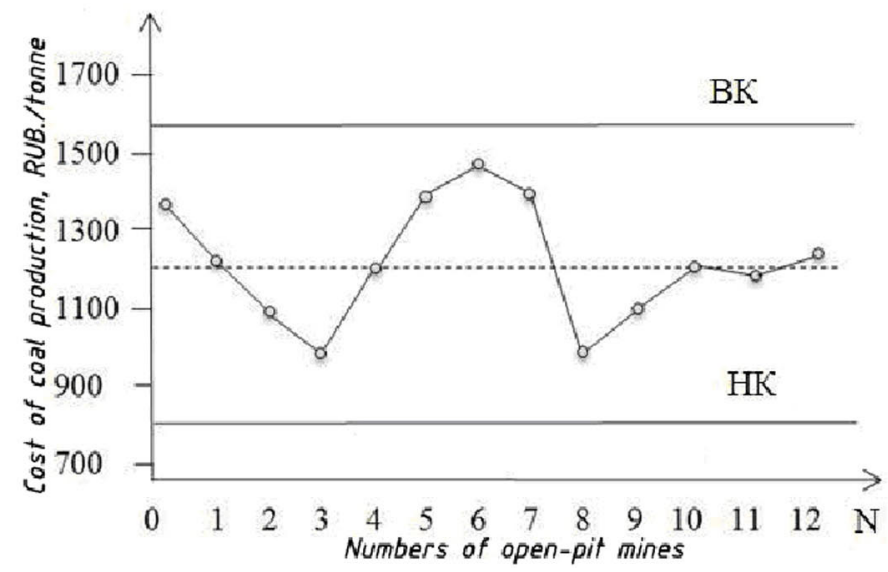

Fig. 4. Control card of indicators for cost of 1 tonne of coal production in a group of coal mining enterprises of Kuzbass

This means that in different time periods the magnitude of the spread of the characteristics considered between individual enterprises is likely to remain, but the position of different enterprises may change, that is, both the leaders and outsiders can change places. As in the previously considered examples, this state of affairs does not at all mean it's satisfactory. On the contrary, the comparison of the obtained characteristics with the requirements of the market shows that some of the enterprises considered do not satisfy the conditions of competitiveness. From the point of view of the traditional logic of management, one should expect an inadvertent reaction from the leadership to find out the causes and who to be blamed for "low efficiency" of these enterprises, to carry out measures for their recovery or closure. It is possible that in a situation of "extinguishing a fire" in the event of a threat to the survival of the whole company, such actions may be justified. However, from the perspective of the theory of variability, this approach will be equivalent to using the traditional "rejection" method. This "management trick", creating the illusion of going out of the situation, often at the expense of significant additional costs, leaves aside the consideration of the causal factors of the appearance of the problem.

Namely: the existing coal mining system, which includes the methodology of design, management and organization of labor, the technology of mining will inevitably lead to the appearance of this average level and dispersion and labor productivity, and the cost of 1 ton of coal at individual enterprises. The solution of the problem, therefore, is not in the search for the allegedly "special reasons" of the poor performance of individual enterprises, but in a qualitative change in the system common to all, which determines their technical and economic efficiency.

\section{Conclusion}

A well-known consultant in the field of modern management and one of the authors of the new generation of management science - quality management E. Deming, very briefly and clearly formulated the main idea of business success as follows: "If I had to express my message to management in only a few words, I would say: "The whole point is in decreasing the variations".

Developing control cards, W. Shewhart set the task to improve the quality of products by reducing the variability in technological operations. E. Deming developed the idea of W. Shewhart, placing it in the basis of the philosophy of quality management. He proceeded from the fact that the principles of management in social and business systems were subject 
to the same objective laws of variability as processes in technical systems. E. Deming convincingly showed that those who didn't understand the fundamentals of the theory of variability would not be able to work out the right management decision and, thus, could not effectively manage his business.

Using the Shewhart-Deming concept of variability management, managers focus their attention on the "causal factors" that limit the effectiveness of the business system, and, improving processes, achieve a decrease in the variability of parameters and characteristics of the latter. They achieve better use of working time (less breakdowns, adjustments, downtime), better use of materials (less rejects), lower costs for re-work and control. This allowed simultaneously to increase the degree of uniformity (quality) of products, and to reduce its cost. On this basis, the competitiveness of producers is being created and the chain reaction of a qualitatively different, much more effective economic strategy is triggered - the strategy of continuous improvement of processes and systems.

The Russian industry and the economy as a whole have yet to understand and master these principles. Obviously, the way of their development will not be easy, but it must be walked for survival in an open market economy, for cooperation and rivalry with those for whom these principles have become the norm of life. Knowledge and adherence to these principles is what will ultimately separate the ascent to success from the trajectory of fall for any organization and including the operations in the coal industry.

\section{References}

1. V. Feigenbaum, Total Quality Control (McGraw Hill Inc. 1983)

2. J. M. Juran, Juran on Leadership for Quality, New York City: The Free Press (1983)

3. W. E. Deming, Out of the Crisis, Cambridge, Mass.: MIT Center for Advanced Engineering Study (1986)

4. T. Ohno Toyota Production System, Productivity Press (1988)

5. John S. Oakland, Total Quality Management. The Route to Improving Perforanans. Second Edition (University of Bradford: Management Centre 1993)

6. J.P. Womack and D.T. Jones Lean Thinking. Banish Waste and Create Wealth in Your Corporation (New York at al:, Free Press, 2003)

7. V. Mikhalchenko, Y. Rubanik, IOP Conf. Ser.: Earth and Environ. Sci., 45, 1 (2016)

8. V. Mikhalchenko, Y. Rubanik, N. Osokina, A. Mikhalchenko, Coal-16. Advances in Engineering Research (Atlantis Press, 2016)

9. M. Tribus, The Germ theory of management (SPC Press, 1992)

10. W.A. Shewhart, Economic Control of Quality of Manufactured Product (Milwaukee, WI: ASQ Quality Press, 1931, reprint 1980)

11. W.A. Shewhart, Statistical Method from the Viewpoint of Quality Control (N.Y., Dover Publications, Inc., 1939, reprint 1986)

12. Henry R Neave, The Denting Dimension (SPC Press, Knoxville, Tennessee 1990)

13. R. Futami, Rep. of Statistical Application Research, JUSE, 33, 2 (1986)

14. Y. Nayatani, Rep. of Statistical Application Research, JUSE, 33, 1 (1986)

15. D. Wheeler, Understanding variations. The Key to Managing Chaos (SPC Press, 1991)

16. D. Wheeler, Advanced Topics in Statistical Process Control (SPC Press 1995) 